\title{
The Diagnostic Significance of Serum Alcohol Dehydrogenase Isoenzymes and Aldehyde Dehydrogenase Activity in Urinary Bladder Cancer Patients
}

\author{
KAROLINA ORYWAL ${ }^{1}$, WOJCIECH JELSKI ${ }^{1}$, TADEUSZ WEREL ${ }^{2}$ and MACIEJ SZMITKOWSKI ${ }^{1}$ \\ Departments of ${ }^{1}$ Biochemical Diagnostics and ${ }^{2}$ Urology, Medical University of Bialystok, Bialystok, Poland
}

\begin{abstract}
Background: The aim of this study was to investigate a potential role of alcohol dehydrogenase and aldehyde dehydrogenase as tumor markers for urinary bladder cancer. Materials and Methods: Serum samples were obtained from 41 patients with bladder cancer and 52 healthy individuals. Class III and IV of ADH and total ADH activity were measured by the photometric method. For measurement of class I and II ADH and ALDH activity, the fluorometric method was employed. Results: Significantly higher total activity of $A D H$ was found in sera of both, low-grade and high-grade bladder cancer patients. The diagnostic sensitivity for total ADH activity was $81.5 \%$, specificity $98.1 \%$, positive $(P P V)$ and negative (NPV) predictive values were $97.4 \%$ and $92.3 \%$ respectively. Area under ROC curve for total $A D H$ activity was 0.848. Conclusion: A potential role of total $A D H$ activity as a marker for bladder cancer, is herein proposed.
\end{abstract}

Urothelial cell carcinoma of the bladder is the second most common malignancy of the genitourinary tract and the leading cause of morbidity and mortality in urinary tract tumors (1). Approximately $75 \%$ of bladder cancers are low-grade, nonmuscle invasive, however, nearly half of cases will recur. Thirty percent of recurrent tumors may show progression to high grade, which is associated with poor prognosis (2). Standard methods for diagnosis of bladder cancer involve cytological evaluation of urine, imaging tests and cystoscopy, but their sensitivity is not satisfying (3). An ideal non-invasive test should be sensitive, specific, rapid, technically simple and noncancer conditions must have little influence on its accuracy. A

Correspondence to: Karolina Orywal, Department of Biochemical Diagnostics, Medical University of Bialystok, Waszyngtona 15 A, PL 15-276 Bialystok, Poland. Tel: +48 857450987, Fax: +48 857450585, e-mail: orywalk@umb.edu.pl

Key Words: Alcohol dehydrogenase isoenzymes, aldehyde dehydrogenase, urinary bladder cancer, cancer markers, diagnostic utility. tumor marker should have additional value, if it could detect biologic change from low-risk to high-risk disease and permit early identification of those patients with high-risk cancer likely to progress in earlier and curable stages of disease.

A literature review shows that ethanol consumption might be a risk factor for urinary bladder cancer (4-6). The one of hypothesis of alcohol-related carcinogenesis might be that increased alcohol metabolism leads to elevated production of carcinogenic acetaldehyde, what is the consequence of disturbances in alcohol dehydrogenase (ADH) and aldehyde dehydrogenase (ALDH) activities (7). Besides, changes in the enzyme activities can also influence cancer development because of causing disorders in the metabolism of many biologically-important substances e.g. retinoic acid. In our previous investigations we observed that alcohol dehydrogenase and aldehyde dehydrogenase activities are present in cancer cells of the urinary bladder. In addition, the activity of class III ADH isoenzyme and total ADH were significantly higher in cancer cells than in healthy tissue while the activity of ALDH was not changed. Many studies show that cancer cells of many organs may release ADH isoenzymes to the blood what is the reason of elevated activity of the specific isoenzymes in the sera of cancer patients. The significant increase of these isoenzymes activities in the sera creates the possibility of application ADH activity measurement in the cancer diagnostics.

While various markers have been studied for urinary bladder cancer, the diagnostic significance of ADH isoenzymes and ALDH activity have not been reported. In the current study, we determined the diagnostic utility of $\mathrm{ADH}$ isoenzymes in urinary bladder cancer. We defined diagnostic sensitivity, specificity, accuracy, predictive value of positive and negative results, and receiver-operating characteristics (ROC) curve of tested enzymes.

\section{Materials and Methods}

Patients. Blood samples were obtained before cancer resection from 41 patients with bladder cancer (mean age $=66$ years, range $=52-92$ 
years), hospitalized in Clinical University Hospital in Białystok, Poland. All patients were diagnosed as urothelial cell carcinoma. The patients were divided into two groups: 16 patients were classified as low-grade and 25 as a high-grade bladder cancer. Nineteen of 41 patients were current smokers, 9 were ex-smokers and 13 were lifelong non-smokers. None of the patients had received chemotherapy, radiotherapy or immunotherapy before sample collection. The control group was composed of blood samples taken from 60 healthy subjects ( 40 men and 20 women; mean age 58 years, range 51-68 years old). All of the patients from studied and control group had a history of only occasional alcohol consumption.

The research protocol was approved by the Medical University of Białystok's Human Care Committee located in Bialystok, Poland (Approval No R-I-002/267/2015). All patients gave their informed consent for the examination.

Determination of total ADH activity. Total ADH activity was estimated by the photometric method using p-nitrosodimethylaniline (NDMA) as a substrate (8). The reaction mixture $(2 \mathrm{ml})$ contained serum $(0.1 \mathrm{ml}), 1.8 \mathrm{~mL}$ of a $26 \mu \mathrm{M}$ solution of substrate in $0.1 \mathrm{M}$ of sodium phosphate buffer, $\mathrm{pH} 8.5$ and $0.1 \mathrm{~mL}$ of mixture containing $0.25 \mathrm{M} \mathrm{n}$-butanol and $5 \mathrm{mM}$ NAD. The reduction of NDMA was monitored at $440 \mathrm{~nm}$ on a Shimadzu UV/VIS 1202 spectrophotometer (Shimadzu Europa GmbH, Duisburg, Germany).

Determination of total ALDH activity. Aldehyde dehydrogenase activity was measured using the fluorogenic method based on the oxidation of 6-methoxy-2-naphtaldehyde to fluorescent 6methoxy-2-naphtoate (9). The reaction mixture contained $60 \mu \mathrm{l}$ of serum, $60 \mu \mathrm{l}$ of substrate, $20 \mu \mathrm{l}$ of $11.4 \mathrm{mM}$ NAD and $2.8 \mathrm{ml}$ of $50 \mathrm{mM}$ of sodium phosphate buffer, $\mathrm{pH} 8.5$. The mixture also contained $50 \mu \mathrm{l}$ of a $12-\mathrm{mM}$ solution of 4-methylpyrazole as a specific inhibitor of ADH activity. The fluorescence was read at an excitation wavelength of 310 and an emission wavelength of $360 \mathrm{~nm}$ on a Shimadzu RF-5301 spectrofluorophotometer (Shimadzu Europa GmbH, Duisburg, Germany).

Determination of Class I and II ADH isoenzymes. Class I and II $\mathrm{ADH}$ isoenzyme activity was measured using fluorogenic substrates (4-methoxy-1-naphthaldehyde for class I and 6-methoxy-2naphthaldehyde for class II) in a reduction reaction according to Wierzchowski et al. (10). The assays were performed in a reaction mixture containing a serum $(60 \mu \mathrm{l})$, substrate $(150 \mu \mathrm{l}$ of $300 \mu \mathrm{M})$, NADH $(100 \mu \mathrm{l}$ of $1 \mathrm{mM})$ and $0,1 \mathrm{M}$ of sodium phosphate buffer, pH 7.6 (2.69 ml) using the conditions previously described (11). The measurements were performed on a Shimadzu RF-5301 spectrofluorophotometer at an excitation wavelength of $316 \mathrm{~nm}$ for both substrates and emission of $370 \mathrm{~nm}$ for class I and $360 \mathrm{~nm}$ for class II isoenzymes.

Determination of Class III ADH isoenzyme. The assay mixture for class III alcohol dehydrogenase contained a serum (100 $\mu \mathrm{l})$, formaldehyde as a substrate $(100 \mu \mathrm{l}$ of $1 \mathrm{mM})$, glutathione $(100 \mu \mathrm{l}$ of $1 \mathrm{mM})$ and NAD $(240 \mu \mathrm{l}$ of $1.2 \mathrm{mM})$ in $0.1 \mathrm{~mol} \mathrm{NaOH}-$ pyrophosphate buffer $\mathrm{pH} 8.0$ (12). The final volume was $2 \mathrm{ml}$. The reduction of NAD was monitored at $340 \mathrm{~nm}$ and $25^{\circ} \mathrm{C}$ on a Shimadzu UV/VIS 1202 spectrophotometer.

Determination of Class IV ADH isoenzyme. The assay mixture for class IV of ADH activity contained serum $(50 \mu \mathrm{L}), \mathrm{m}-$ nitrobenzaldehyde as a substrate $(132 \mu \mathrm{L}$ of $80 \mu \mathrm{M})$ and NADH (172 $\mu \mathrm{L}$ of $86 \mu \mathrm{M})$ in $0.1 \mathrm{M}$ sodium phosphate buffer $\mathrm{pH} 7.5$ (13). The oxidation of NADH was monitored at $340 \mathrm{~nm}$ and $25^{\circ} \mathrm{C}$ on a Shimadzu UV/VIS 1202 spectrophotometer.

Diagnostic value calculation. The diagnostic criteria, such as the diagnostic sensitivity, diagnostic specificity, predictive value of positive (PPV) and negative (NPV) results and the ROC curve, were determined using GraphRoc Program for Windows (University of Turku, Turku, Finland) (14). For the diagnostic accuracy calculations and the ROC curve we used the total cancer patients group $v s$. control group.

Statistical analysis. Preliminary statistical analysis (Chi-square test) revealed that the distribution of ADH and ALDH activities did not follow a normal distribution. The differences between tested and control groups were evaluated by Mann-Whitney $U$-test. To test the hypothesis about the differences between different grades of bladder cancer, ANOVA rank Kruskal-Wallis test was performed. Data were presented as mean values \pm standard deviation. Statistically significant differences were defined as comparisons resulting in $p<0.05$.

\section{Results}

The activities of total ADH, ALDH and ADH isoenzymes in the sera of patients with urinary bladder cancer are presented in Table I. We found that the total alcohol dehydrogenase activity was significantly higher in patients with bladder cancer compared with healthy subjects. The mean total activity of ADH was $7.92 \mathrm{IU} / 1$ in the sera of cancer patients and $0.95 \mathrm{IU} / 1$ in the control group. We have also observed that ALDH activity did not indicate significant differences between tested groups. The comparison of ADH isoenzymes activities showed that only the activity of ADH I was significantly higher in the serum of cancer patients in contrast to controls. The mean activity of this class ADH was $5.88 \mathrm{mIU} / \mathrm{l}$ in the bladder cancer patients group and $1.89 \mathrm{mIU} / \mathrm{l}$ in the healthy subjects. The other tested classes of ADH isoenzymes had higher activities in the serum of patients with cancer but the differences were not statistically significant $(p>0.05)$.

The analysis of the alcohol dehydrogenase isoenzymes activities in the different grades of urinary bladder cancer showed that the activity of ADH class I was significantly higher only in high-grade bladder cancer group $(6.37 \mathrm{mIU} / \mathrm{l})$ compared to controls. The activity of ADH I was higher also in low-grade patients $(3.18 \mathrm{mIU} / \mathrm{l})$ than in control group but the difference was not significant. The activity of isoenzyme class III ADH was almost 2-times higher in the sera of patients with bladder cancer than in controls but this increase was not statistically significant. The other ADH isoenzymes did not exhibit any characteristic change of activity correlating with grade of bladder cancer. In contrast, significantly higher $(p<0.05)$ total activity of ADH was found in the sera of both, low-grade (7.89 IU/l) and high-grade bladder cancer patients (8.72 IU/l), in comparison to healthy volunteers. The total 
Table I. Comparison of ADH isoenzymes and ALDH activities in the sera of bladder cancer patients.

\begin{tabular}{|c|c|c|c|c|c|c|}
\hline Tested group & $\begin{array}{c}\text { ADH I } \\
\text { Mean } \pm \text { SD }\end{array}$ & $\begin{array}{c}\text { ADH II } \\
\text { Mean } \pm \text { SD }\end{array}$ & $\begin{array}{c}\text { ADH III } \\
\text { Mean } \pm \text { SD }\end{array}$ & $\begin{array}{c}\text { ADH IV } \\
\text { Mean } \pm \text { SD }\end{array}$ & $\begin{array}{c}\text { ADH Total } \\
\text { Mean } \pm \text { SD }\end{array}$ & $\begin{array}{l}\text { ALDH Total } \\
\text { Mean } \pm \text { SD }\end{array}$ \\
\hline Bladder cancer $(n=41)$ & $5.88 \pm 7.54$ & $16.82 \pm 10.77$ & $15.94 \pm 15.77$ & $14.68 \pm 16.21$ & $7.92 \pm 7.75$ & $8.44 \pm 7.38$ \\
\hline Low-grade $\mathrm{BCa}(\mathrm{n}=16)$ & $3.18 \pm 6.03$ & $15.54 \pm 14.27$ & $8.53 \pm 4.13$ & $13.17 \pm 14.06$ & $7.89 \pm 7.72$ & $7.96 \pm 8.17$ \\
\hline High-grade $\mathrm{BCa}(\mathrm{n}=25)$ & $6.37 \pm 9.78$ & $16.39 \pm 9.64$ & $17.54 \pm 16.12$ & $16.76 \pm 19.37$ & $8.72 \pm 7.84$ & $10.99 \pm 11.61$ \\
\hline \multirow[t]{5}{*}{ Control group $(n=60)$} & $1.89 \pm 0.92$ & $14.01 \pm 3.37$ & $8.89 \pm 2.53$ & $12.18 \pm 3.87$ & $0.95 \pm 0.48$ & $7.23 \pm 2.45$ \\
\hline & $p^{\mathrm{a}}=0.012$ & $p^{\mathrm{a}=}=0.152$ & $p^{\mathrm{a}}=0.628$ & $p^{\mathrm{a}}=0.158$ & $p^{\mathrm{a}}<0.001$ & $p^{\mathrm{a}}=0.561$ \\
\hline & $p^{\mathrm{b}}=0.097$ & $p^{\mathrm{b}}=0.097$ & $p^{\mathrm{b}}=0.611$ & $p^{\mathrm{b}}=0.727$ & $p^{\mathrm{b}}=0.046$ & $p^{\mathrm{b}}=0.668$ \\
\hline & $p^{\mathrm{c}}=0.017$ & $p^{\mathrm{c}}=0.211$ & $p^{\mathrm{c}}=0.188$ & $p^{\mathrm{c}}=0.216$ & $p^{c}<0.001$ & $p^{\mathrm{c}}=0.864$ \\
\hline & $p^{\mathrm{d}}=0.202$ & $p^{\mathrm{d}}=0.204$ & $p^{\mathrm{d}}=0.205$ & $p^{\mathrm{d}}=0.579$ & $p^{\mathrm{d}}=0.691$ & $p^{\mathrm{d}}=0.766$ \\
\hline
\end{tabular}

$\mathrm{SD}$, Standard deviation; $\mathrm{BCa}$, bladder cancer. Statistically significant differences were defined as comparisons resulting in $p<0.05$. Data are expressed as mIUl/l (ADH total- IU/l). $p^{\mathrm{a}}$, cancer patients $v s$. controls; $p^{\mathrm{b}}$, low-grade $\mathrm{BCa} v s$. controls; $p^{\mathrm{c}}$, high-grade $\mathrm{BCa} v s$. controls; $p^{\mathrm{d}}$, low-grade $\mathrm{BCa}$ vs. high-grade BCa.

Table II. Diagnostic criteria for ADH total and ADH I for urinary bladder cancer.

\begin{tabular}{lcccccc}
\hline & $\begin{array}{c}\text { Cut-off } \\
{[\mathrm{mIU} / \mathrm{l}]}\end{array}$ & $\begin{array}{c}\text { Diagnostic sensitivity } \\
{[\%]}\end{array}$ & $\begin{array}{c}\text { Diagnostic specificity } \\
{[\%]}\end{array}$ & $\begin{array}{c}\text { Positive predictive value } \\
{[\%]}\end{array}$ & $\begin{array}{c}\text { Negative predictive value } \\
{[\%]}\end{array}$ & $\begin{array}{c}\text { Accuracy } \\
{[\%]}\end{array}$ \\
\hline ADH I & 12.19 & 29.6 & 44.1 & 57.2 & 52.3 & 49.1 \\
ADH total & 2280 & 81.5 & 98.1 & 97.4 & 92.3 & 89.7 \\
\hline
\end{tabular}

activity of ALDH also did not indicate significant differences between different grades of disease.

Table II shows the diagnostic criteria for ADH total and ADH I. The sensitivity (81.5\%) and specificity (98.1\%) of total $\mathrm{ADH}$ were much higher than values for isoenzyme class I ( $29.6 \%$ and $44.1 \%$, respectively). Both the predictive value of positive and negative results were also the highest for the total activity of ADH (97.4\% and 92.3\%). The accuracy was $89.7 \%$ for the total $\mathrm{ADH}$ activity and only $49.1 \%$ for $\mathrm{ADH}$ I activity.

The relationship between diagnostic sensitivity and specificity was illustrated by a ROC curve (Figure 1). It shows that area under the ROC curve for the total ADH activity (0.848) was much higher than the ROC area of isoenzymes class I (0.333).

\section{Discussion}

Urinary bladder cancer is a socially-significant healthcare problem. Bladder cancers are commonly investigated due to presenting symptoms such as haematuria, urinary frequencies, pain or burning during urination or lower back pain on one side of the body. Cystoscopy along with cytology is the "gold standard" for bladder cancer diagnosing. Cytology is specific for this disease diagnosis but less sensitive particularly in low-grade disease. On the other hand, cystoscopy is invasive and relatively costly method. Therefore, it prompts the search for simple, non-invasive, highly sensitive and specific markers of bladder cancer.

In previous experiments, we have seen a significant increased activity of total alcohol dehydrogenase and its isoenzyme class III in bladder cancer cells. Significantly higher total activity of ADH was found in both, low-grade and high-grade bladder cancer, in comparison to healthy bladder tissues. We found that the total activity of alcohol dehydrogenase is significantly higher in the sera of bladder cancer patients compared to control group. Significantly higher activity of total ADH was stated in the sera of both, patients with low-grade and high grade bladder cancer. Many data have shown that cancer cells have the ability to release alcohol dehydrogenase isoenzymes to the blood of patients in response to cancer conditions (7). This suggests that increased ADH activity in the sera of bladder cancer patients may be the result of enzyme being released from cancer cells.

Moreover, we found that the activity of isoenzyme class I $\mathrm{ADH}$ was also significantly elevated in the sera of total group of patients with bladder cancer compared to controls. It is interesting that the activity of ADH I was significantly higher only in the sera of high-grade bladder cancer patients and was not essential changed in the low-grade group. It is interesting that in high-grade bladder cancer tissue, we stated significantly elevated activity of isoenzyme class III ADH but in the sera of these patients, we found 2-times increased level of ADH III 


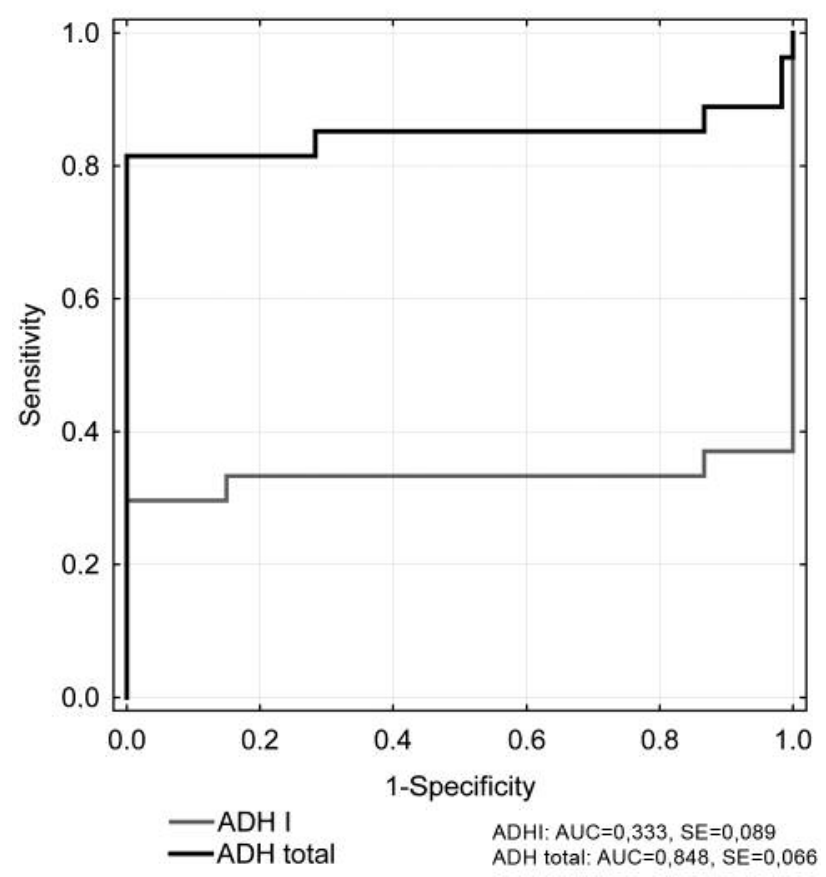

Figure 1. Receiver-operating characterististics (ROC) curves for alcohol dehydrogenase class $I(A D H I)$ and total alcohol dehydrogenase (ADH total). AUC (area under curve); SE (standard error of the mean).

activity but the difference was not significant. Furthermore, in the sera of high-grade patients, we have stated significantly elevated activity of ADH class I. High-grade bladder cancer has a strong tendency to invade the muscular wall of the bladder and at least half of high-grade patients develop local and distant metastasis (15). Higher activity of class I ADH may appear as a result of releasing this isoenzyme from metastatic tumours e.g. liver. Data demonstrated by Chrostek et al. and Jelski et al. show that serum activity of class I ADH isoenzymes was significantly higher in patients with metastatic liver tumors and in primary tumors $(16,17)$. We can assume that significant increase of the total ADH activity in the sera of bladder cancer patients, may be a result of ADH III, being released from bladder cancer cells and ADH I, being excreted from metastatic tumor.

Molecules associated with urinary bladder cancer growth and progression may serve as a basis for designing noninvasive diagnostic tests. The ideal cancer marker should be characterized by high specificity (not detectable in healthy people) and high sensitivity (indicate early stage of the disease). Urinary cytology has its place as the additive diagnostic tool to cystoscopy. Cytology is characterized by the relatively low sensitivity (38\%), but its specificity is highest of all bladder cancer markers (98.3\%) (18). In our study, we defined that sensitivity of total ADH activity is $81.5 \%$ and its specificity is similar to that of cytology $-98.1 \%$. The literature data show that diagnostic significance of the urinary bladder cancer biomarkers is the subject of many researches. Bladder tumor antigen test (BTA TRAK and BTA stat) has been approved for use as an adjunctive test in the management of bladder cancer along with cystoscopy (19). But sensitivity and specificity of BTA test are lower than that of total ADH activity. Systematic review has revealed a sensitivity of $70 \%$ and specificity of $75 \%$ for BTA Stat and lower for BTA TRAK (66\% and 65\%, respectively) (20). Moreover, hyaluronidase (HAse), enzyme catalyzing hyaluronic acid degradation, has been detected in the urine of patients with bladder cancer. HAse test reveals the same sensitivity as ADH but its specificity is lower $(83.8 \%)$ (21). Next approved test for bladder cancer diagnostics is nuclear mitotic apparatus protein 22 (NMP22) which sensitivity varies from $68.5 \%$ to $88.5 \%$ and specificity varies from $65.2 \%$ to $91.3 \%$. These values are similar to that we have obtained in connection with ADH activity. Negative predictive value (77.9\%-98\%) is also similar to ADH activity (92.3\%) but positive predictive value is higher for ADH than for NMP22 (97.4\% and 34\% -76\%, respectively) (19). CYFRA 21-1 (cytokeratin 19 fragment) is detected in the serum and urine of bladder cancer patients and has been investigated as a marker for this malignancy. The sensitivities for serum and urine CYFRA 21-1 were $42 \%$ and $82 \%$, respectively; and specificities, $94 \%$ and $80 \%$, respectively (22).

The most important criterion for tumor markers is the ROC curve. The area under the ROC curve (AUC) indicates the clinical usefulness of tested substances. In this study, the area under the ROC curve for total ADH activity was 0,848 and was higher than for cytology (AUC=0.66-0.74), matrix metalloproteinase MMP-9 (AUC $=0.68$ ) or molecular marker - Ki (AUC=0.71) (23-25). The AUC for the total ADH activity was similar to that for serum and urine CYFRA 211 (0.88 and 0.87 , respectively) (22).

Alcohol dehydrogenase and its isoenzymes as tumor markers were studied in the other urologic cancer - renal cell carcinoma (RCC). The diagnostic criteria of total ADH activity in renal cancer were much lower than that in bladder cancer. The sensitivity was $67.11 \%$, specificity $72.54 \%$, positive predictive value $68.66 \%$ and negative predictive value $65.48 \%$. Higher values were for the activity of isoenzyme class I ADH (sensitivity $73.36 \%$, specificity $85.61 \%$, PPV $79.12 \%$ and NPV 75.3\%). Also AUC for total ADH (0.689) and ADH I (0.748) was lower than for total ADH in bladder cancer (26). Our results show that ADH I cannot be considered as marker useful for bladder cancer diagnostics but the total ADH activity reveals promising value.

A tumor marker may be useful for diagnosis if is highly specific and highly sensitive to the tumor type. The activity of total alcohol dehydrogenase reveals high sensitivity and very high specificity, similar to that demonstrated by markers already incorporated in routine clinical practice. Moreover, 
$\mathrm{ADH}$ activity increases together with progression of disease what give additional value to its meaning. The test is cheap and specimens are easily obtainable. The main utility of ADH activity measurement in clinical medicine could support the diagnosis or reflect tumor progression. Together with class I $\mathrm{ADH}$ activity, it could also indicate the presence of liver metastasis. Attempts to improve the sensitivity and specificity, the combination of ADH activity with other procedures could be used for urinary bladder cancer diagnosis.

This is the first study presenting all the diagnostic criteria for alcohol dehydrogenase and aldehyde dehydrogenase in bladder cancer. Although currently non-invasive bladder cancer tests cannot replace cystoscopy, alcohol dehydrogenase activity has shown a promise in being clinically useful.

\section{References}

1 Siegel RL, Miller KD and Jemal A: Cancer Statistics, 2017. CA Cancer J Clin 67: 7-30, 2017.

2 Lopez-Beltran A, Marques RC, Montironi R, Reymundo C, Fonseca $\mathrm{J}$ and Cheng L: Dysplasia and carcinoma in situ of the urinary bladder. Anal Quant Cytopathol Histpathol 37: 29-38, 2015.

3 Babjuk M, Burger M, Zigeuner R, Shariat SF, van Rhijn BW, Comperat E, Sylvester RJ, Kaasinen E, Böhle A, Palou Redorta $\mathrm{J}$ and Rouprêt M: European Association of Urology. EAU guidelines on non-muscle-invasive urothelial carcinoma of the bladder: update 2013. Eur Urol 64: 639-653, 2013.

4 Pelucchi C and La Vecchia C: Alcohol, coffee, and bladder cancer risk: a review of epidemiological studies. Eur J Cancer Prev 18: 62-68, 2009.

5 Masaoka H, Ito H, Soga N, Hosono S, Oze I, Watanabe M, Tanaka H, Yokomizo A, Hayashi N, Eto M and Matsuo K: Aldehyde dehydrogenase 2 (ALDH2) and alcohol dehydrogenase 1B (ADH1B) polymorphisms exacerbate bladder cancer risk associated with alcohol drinking: gene-environment interaction. Carcinogenesis 37: 583-588, 2016.

6 Zaitsu M, Nakamura F, Toyokawa S, Tonooka A, Takeuchi T, Homma Y and Kobayashi Y: Risk of Alcohol Consumption in Bladder Cancer: Case-Control Study from a Nationwide Inpatient Database in Japan. Tohoku J Exp Med 239 :9-15, 2016.

7 Orywal K and Szmitkowski M: Alcohol dehydrogenase and aldehyde dehydrogenase in malignant neoplasms. Clin Exp Med 17: 131-139, 2017.

8 Skursky L, Kovar J and Stachova MA: Sensitive assay for alcohol dehydrogenase activity in blood serum. Anal Biochem 89: 65-71, 1979.

9 Wierzchowski J, Wroczyński P, Laszuk K and Interewicz E: Fluorimetric detection of aldehyde dehydrogenase activity in human blood, saliva, and organ biopsies and kinetic differentiation between class I and II isozymes. Anal Biochem 245: 69-78, 1997.

10 Wierzchowski J, Dafeldecker W, Holmquist B and Vallee BL: Fluorimetric assay for isozymes of human alcohol dehydrogenase. Anal Biochem 178: 57-62, 1989.

11 Jelski W, Laniewska-Dunaj M, Orywal K, Kochanowicz J, Rutkowski R and Szmitkowski M: The diagnostic value of alcohol dehydrogenase (ADH) isoenzymes and aldehyde dehydrogenase (ALDH) measurement in the sera of patients with brain tumor. Arch Med Sci 13: 346-352, 2017.
12 Koivusalo M, Baumann M and Uotila L: Evidence for the identity of glutathione-dependent formaldehyde dehydrogenase and class III alcohol dehydrogenase. FEBS Lett 257: 105-109, 1989.

13 Dohmen K, Baraona E, Ishibashi H, Pozzato G, Moretti M, Matsunaga C, Fujimoto $\mathrm{K}$ and Lieber CS: Ethnic differences in gastric $\sigma$-alcohol dehydrogenase activity and ethanol first metabolism. Alcohol Clin Exp Res 20: 1569-1576, 1996.

14 Kairisto V, Virtanen A, Uusipaikka E, Voipio-Pulkki LM, Näntö $\mathrm{V}$, Peltola $\mathrm{O}$ and Irjala $\mathrm{K}$ : Method for determining reference changes from patients' several data: Example of cardiac enzymes. Clin Chem 39: 2298-2304, 1993.

$15 \mathrm{Wu}$ XR: Urothelial tumorigenesis: a tale of divergent pathways. Nat Rev Cancer 5: 713-725, 2005.

16 Chrostek L and Szmitkowski M: The activity of class I and II alcohol dehydrogenase isoenzymes in the sera of patients with liver tumours. Clin Chem Lab Med 38: 409-412, 2000.

17 Jelski W, Zalewski B and Szmitkowski M: Alcohol dehydrogenase $(\mathrm{ADH})$ isoenzymes and aldehyde dehydrogenase (ALDH) activity in the sera of patients with liver cancer. JCLA 22: 204-209, 2008.

18 Planz B, Jochims E, Deix T, Caspers HP, Jakse G and Boecking A: The role of urinary cytology for detection of bladder cancer. Eur J Surg Oncol 31: 304-308, 2005.

19 Dey P: Urinary markers of bladder carcinoma. Clin Chim Acta 340: 57-65, 2004.

20 Van Rhijn BW, van der Poel HG and van der Kwast TH: Urine markers for bladder cancer surveillance: a systematic review. Eur Urol 47: 736-748, 2005.

21 Lokeshwar VB, Obek C, Pharm HT, Wei D, Young MJ, Duncan RC, Soloway MS and Block NL: Urinary hyaluronic acid and hyaluronidase: markers for bladder cancer detection and evaluation grade. J Urol 163: 348-356, 2000.

22 Huang YL, Chen J, Yan W, Zang D, Qin Q and Deng AM: Diagnostic accuracy of cytokeratin-19 fragment (CYFRA 21-1) for bladder cancer: a systematic review and meta-analysis. Tumour Biol 36: 3137-3145, 2015.

23 McCroskey Z, Pambuccian SE, Kleitherms S, Antic T, Cohen MB, Barkan GA and Wojcik EM: Accuracy and interobserver variability of the cytologic diagnosis of low-grade urothelial carcinoma in instrumented urinary tract cytology specimens. Am J Clin Pathol 144: 902-908, 2015.

24 Candido S, Di Maso M, Serraino D, McCubrey JA, Bortolus R, Zanin M, Battiston M, Salemi R, Libra M and Polesel J: Diagnostic value of neutrophil gelatinase-associated lipocalin/ matrix metalloproteinase-9 pathway in transitional cell carcinoma of the bladder. Tumour Biol 37: 9855-9863, 2016.

25 Schmidt J, Propping C, Siow WY, Lohse-Fischer A, Toma M, Baldauf-Twelker A, Hakenberg OW, Wirth MP and Fuessel S: Diagnostic and prognostic value of bladder cancer-related transcript markers in urine. J Cancer Res Clin Oncol 142: 401414, 2016.

26 Orywal K, Jelski W, Werel $\mathrm{T}$ and Szmitkowski M: The diagnostic significance of serum alcohol dehydrogenase isoenzymes and aldehyde dehydrogenase activity in renal cell cancer patients. Exp Mol Path 100: 416-420, 2016.

Received April 27, 2017

Revised May 13, 2017

Accepted May 16, 2017 